\title{
GÉRARD SEGHERS: PINTOR EN GRANDE Y EN PEQUEÑO. NUEVAS PINTURAS IDENTIFICADAS
}

Gérard Seghers (Amberes, 1591-1651), pintor del círculo de Rubens con maneras propias de su escuela, empezó a despertar interés en los años 1930, cuando L. Roblot-Delondre le dedicó un artículo en la Gazette des Beaux Arts ${ }^{1}$. Poco era lo que de él se conocía hasta entonces ${ }^{2}$. Siguieron las publicaciones de D. Roggen, H. Pauwels y B. Nicolson, que abordaron el estilo caravaggesco del pintor $^{3}$. Entre los trabajos más recientes que han contribuido al corpus del maestro, cabe destacar los estudios de Hans Vlieghe ${ }^{4}$, Matías Díaz Padrón ${ }^{5}$, Jacques Foucart ${ }^{6}$, Carl van de Velde ${ }^{7}$, Arnout Balis $^{8}$, y Anne Delvingt ${ }^{9}$, así como la monografía de Dorothea Bieneck publicada en $1992^{10}$.

La primera obra que nos ocupa hoy es una Virgen con Niño (Fig. 1) ${ }^{11}$ del coleccionismo madrileño, tenida como anónima, en la que nos fue posible reconocer los modelos y maneras propias del pintor. Sentada de tres cuartos, la Virgen sostiene al Niño Jesús con su brazo izquierdo.

${ }^{1}$ L. Robloy-DÉlondre, “Gerard Seghers”, Gazette des Beaux-Arts, 1930, pp. 184-199.

2 G. GLÜCK, "Aus Rubens' Zeit und Schule. Bemerkungen zu einigen Gemälden der Kaiserlichen Galerie in Wien. I. Gerard Zeghers“, Jahrbuch der Kunsthistorischen Sammlungen des Allerhöchsten Kaiserhouses, XXIV, n 1, 1903, pp. 3-11.

${ }^{3}$ D. RogGen \& H. Pauwels, "Het Caravagistisch oeuvre van Gerard Seghers", Gentse bijdragen tot de kunstgeschiedenis, XVI, 1955-1956, pp. 255-301. Véase también, B. Nicolson, "Gerard Seghers and the Denial of St. Peter", The Burlington Magazine, CXIII, 1971, pp. 304-309.

4 H. VLIEGHE, «Enkele aantekeningen betreffende Florent le Comte's relaas over de reis van Gerard Seghers naar Italië en Spanije", Bijdragen tot de geschiedenis inzonderheid van het Oud Hertogdom Brabant, 3, 1963, pp. 211-214; "Rubens activity for the Ghent Jesuits in 1633", The Burlington Magazine, Julio 1969, pp. 427-435; "Een Pastorale door Gerard Seghers", Jaarboek van het Koninklijk Museum voor Schone Kunsten Antwerpen, 1976, pp. 297-304.

5 M. Díaz Padrón, Pintura flamenca del siglo XVII en España, Tesis Doctoral, Universidad Complutense de Madrid, 1975, Tesis Doctoral inédita, vol. III, pp. 1017 y ss; Idem, "Un retrato ecuestre de don Diego de Messía, de Pierre Sanyers, y un San Pedro Penitente de Gérard Seghers en Castres y la Catedral de Sevilla", Goya, 152, 1979, pp. 7879; Idem, "Presencia y obra de Gérard Seghers en la España de los Austrias", Congreso Hispano-Belga, 1981; Idem, "Dos bocetos de Thomas Willeboirts Bosschaert y de Gerard Seghers atribuidos a Van Dyck en el Museo de Picardie y colección Koetser", Archivo Español de Arte, 1980, n 209, LIII, pp. 19-26; Idem, "Un lienzo de Gerard Seghers atribuido a Rubens en la Casa de Alba", Archivo Español de Arte, 1985, n 230, LVIII, pp. 108 a 114; Idem, "Una tercera réplica del San Pedro de Gérard Seghers del Museo de Castres", Archivo Español de Arte, 1991, n 256, LXIV, pp. 537539.

6 J. FOUCART, «Quelques œuvres de Gérard Seghers», Essays in Northern European Paintings presented to Egbert Haverkamp-Begeman on his 60th birthday, Groeningen, 1983, pp. 89-93.

7 C. van de Velde, "In de ban van Caravaggio en Rubens : de schilder Gérard Seghers", Revue Belge d'Archéologie et d'histoire de l'Art, LXI, 1992, $\mathrm{p}$; 184;

8 A. BALIS, «Focus: De Droom van H. Jozef door Gerard Seghers”, Museumkrant, 2, mayo 1995, s.p.; «Van Dyck : Some Problems of Attribution», in Van Dyck 350, Symposium Papers of the Center for Advanced Study in the Visual Arts, Washington, 1994, pp. 180-181.

9 A. Delvingt, «Les répliques dans l'œuvre de Gérard Seghers. Au sujet d'un Christ apparaissant à la Vièrge au retour des limbes retrouvé à Schoten", Annales d'Histoire de l'Art \& d'Archéologie, XXII, 2000, pp. 93-107;"Une série d'Apôtres, le Christ et Saint Paul du peintre caravaggesque Gérard Seghers identifiée à Saint Augustin», Revue d'Archéologie et d'Histoire de l'Art de l'Académie royale d'Archéologie de Belgique, Bruselas, LXX, 2001, pp. 143$181 ;$ «Deux toiles peintes par Gérard Seghers pour le couvent des Falcons à Anvers identifiées à Soignes», Gazette des Beaux Arts, 2001, pp. 139-150;Idem, Quatorze tableaux de Gérard Seghers retrouvés, Collection Les immanents art, 2002; «A self-portrait by Gerard Seghers, tres expert peinctre en grand», The Burlington Magazine, 1223, 2005, pp. 112114;Le peintre anversois Gérard Seghers (1591-1651) et l'Espagne. Recherches iconographiques et mise en lumières des échanges de modèles avec peintres anversois et espagnols contemporains, Bruselas, Universidad Libre, Tesis Dotoral bajo la dirección del Profesor Martens (en curso).

10 D. BIENECK, Gerard Seghers 1591-1651. Leben und Werk des Antwerpener Historienmalers, 1992.

${ }^{11}$ Lienzo, 85 x 110 cm. Madrid, Colección privada. 


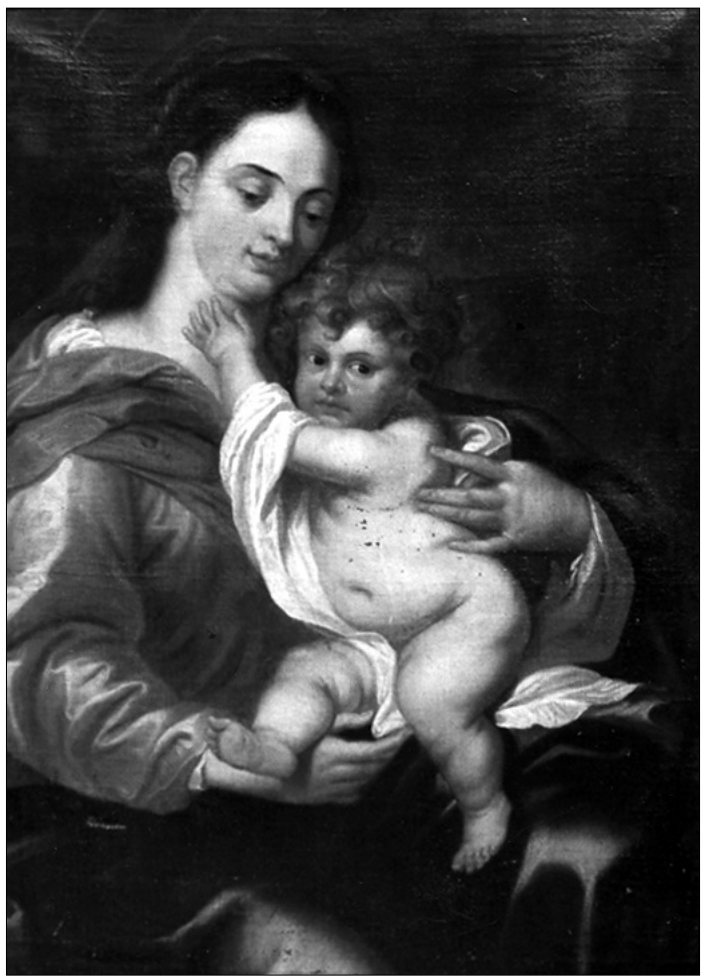

Fig. 1. Gérard Seghers. Virgen con Niño. Madrid, colección particular.

Su mano derecha toma el paño enredado entre las piernas del Niño, que se vuelve, juguetón, hacia ella. En actitud tierna y graciosa, el pequeño acerca su mano para acariciar la barbilla de María. La Virgen viste la clásica indumentaria sagrada del Barroco, con túnica, manto y velo, dejando ver en el brazo derecho la manga del camisón.

El estudio más detenido de la pintura nos condujo a asociarla con un grabado conocido de Paul Pontius, editado en dos ejemplares (Figs. 2 y 3$)^{12}$ y ejecutado a partir de una pintura desaparecida de Gérard Seghers con la Virgen con Niño y Santa Ana. Al margen de los argumentos estilísticos que consideraremos más abajo, el grabado es un documento determinante para apoyar nuestra hipótesis de autoría. En la parte inferior se lee una inscripción en latín con dedicatoria a Peter van den Brouck, junto al nombre del pintor: "Parvule maternis satis est haesisse lacertis, iam decet alternis membra locare toris,/ Nec refugis, licet obijcias tua sceptra Deumquel Nasceris ut puerum fascia parca premat" y, más abajo: "Petro vanden Brouck viro integerrimo artis pictoriae amatori singulari, familiari suo hoc benevolontiae pignus D.D. Gerard. Seghers invent". Probablemente el cuadro estaba en su colección.

La Virgen y Jesús figuran en el grabado sobre un fondo con columna, acompañados por Santa Ana, que mira al Niño junto a la cuna. En el suelo a la izquierda, junto a un gato dormido, está

12 Viena, Albertina, Inv. No. HB 61 (No. 24); París, Bibliothèque Nationale, Cabinet des estampes, Inv. No Cc 39 $\left(n^{\circ}\right.$ 5) [Bieneck, op. cit. 1992, No. A137]. 
el cesto de costura de la Virgen. Al comparar la pintura con el grabado es fácil percibir que la Virgen y el Niño corresponden con exactitud. Pensamos que la pintura que damos hoy a conocer es el fragmento que ha sobrevivido del original que sirvió al grabado y que hasta hoy se tenía por desaparecido. Todo indica que la figura de Santa Ana y el resto del decorado fueron víctimas de una amputación -quizá motivada por algún daño irreparable- como puede verse por el encuadre que corta el brazo en el margen izquierdo del lienzo. El lienzo original debía ser de gran tamaño, dadas las dimensiones del fragmento rescatado.

La calidad de la pintura no ofrece motivos para dudar de que se trate de la composición que reproduce el grabado. El modelo de la Virgen recuerda a los prototipos más frecuentes del pintor. Lleva el cabello suelto y reunido en una trenza recogida alrededor de su cabeza; viste túnica rosada, teñida con delicados matices dorados, y un manto de un azul verdoso, sin duda algo alterado. Un velo vaporoso cae por encima de sus hombros formando gruesos pliegues. La belleza femenina en las obras de Gérard Seghers se dibuja en rostros de corte ovalado y grandes ojos de párpados redondos, a menudo dirigidos hacia abajo, como los que aquí imprimen en el rostro de María la tristeza de un mal presagio. El rostro y busto de la Virgen es muy similar en la Adoración de los Magos de la Iglesia de Nuestra Señora de Brujas ${ }^{13}$, pintura que se fecha un año antes del grabado de Paul Pontius (1631), con dedicatoria a un cliente español, Don Alvaro de Bazán, marqués de Santa Cruz. El modelo del Niño en la pintura que estudiamos deriva también del retablo de Brujas, con la pierna izquierda levantada, la planta del pie aparente, el mismo vientre rollizo, el paño que lo cubre y la mano de la Virgen que lo sostiene. Sólo cambia la posición del Niño, que en la Adoración de los Magos bendice al Melchor, mientras que aquí se vuelve para acariciar a su madre. Encontramos el rostro de la Virgen -aunque con los ojos abiertos y vueltos hacia Jesús- repetido en otra pintura de la primera mitad de la década de 1630 con Cristo y la Virgen del Museo Plantin-Moretus de Amberes ${ }^{14}$.

Prueba de la difusión del grabado de Pontius son las copias que hemos localizado. Una, sobre cobre, se encuentra en colección privada española en mal estado de conservación (Fig. 4) y otra, en lienzo, estuvo en venta antigua de La Haya, registrada como copia libre de Rubens (Fig. 5) ${ }^{15}$. Se trata de una pintura de pobre calidad de mano de un copista con parca destreza. Obsérvese la falta de profundidad en los pliegues de los mantos, el modelado duro en los muslos del niño, la ausencia de los matices de sombras, la dureza de los rostros, y la escasa habilidad con que se representa el gato.

Una pintura con la Virgen y el Niño muy similar en composición poseyó el archiduque Leopoldo Guillermo en Bruselas, hoy perdida pero conocida por la reproducción de David Teniers en el Gabinete de pinturas del archiduque Leopoldo Guilermo ${ }^{16}$; así como por la detallada descripción del inventario de sus colecciones en $1659{ }^{17}$. Salvo por la inversión de las figuras, el cortinaje

\footnotetext{
${ }^{13}$ Lienzo, 405 x $320 \mathrm{~cm}$. Brujas, Catedral de Nuestra Señora [Véase D. Bieneck, Gerard Seghers 1591-1651. Leben und Werk des Antwerpener Historienmalers, 1992, p. 185, No. A71].

${ }^{14}$ Lienzo, 155 x 236 cm. Depósito del Museo Real de Bellas Artes de Amberes [Cat. No. 510], Bieneck, op. cit. 1992, No. A93.

15 Lienzo, 64,5 x 51,5 cm. La Haya, Kunsthandel H. Jüngeling, 1961 (como copia libre de P. P. Rubens). Fue restaurado por C. L. Windt, Beekbergen.

${ }^{16}$ Lienzo, 96 x 125 cm. Palacio de Schleissheim, Staatsgalerie, Inv. No. 1819 [Vid;Bieneck op. cit. 1992, p. 235, No. A141]

17 “No. 710. Ein Stukch in Ouali von Öhlfarb auf Holcz, warin vnnser liebe Fraw in einem rothen Klaidt vnndt blawen Mantel mitt dem Khindtlein Jesv auf ihrem Schosz, welhes die rechte Handt auff ihre Brusst hält. Ohne Rahmen, hoch 4 ? Spann vnndt 3 Spann 4 Finger braidt. Von Gerard Zegers Original". Inventario de la colección del archiduque Leopoldo Guillermo, 1659 [Publicado por A. Berger, "Inventar der Kunstsammlungen des Erzherzogs Leopold Wilhelm von Österreich. Nach der Originalhandschrift im Fürstlich Schwarzenberg'schen Centralarchiv", Jahrbuch der kunsthistorischen Sammlungen des Allerhöchsten Kaiserhauses, I, 1883, p. CXLVIII. [Vid. Bieneck, Op. Cit. 1992, p. 282, Doc. $111 ;$ p. 242, $\mathrm{n}^{\circ}$ B65].
} 


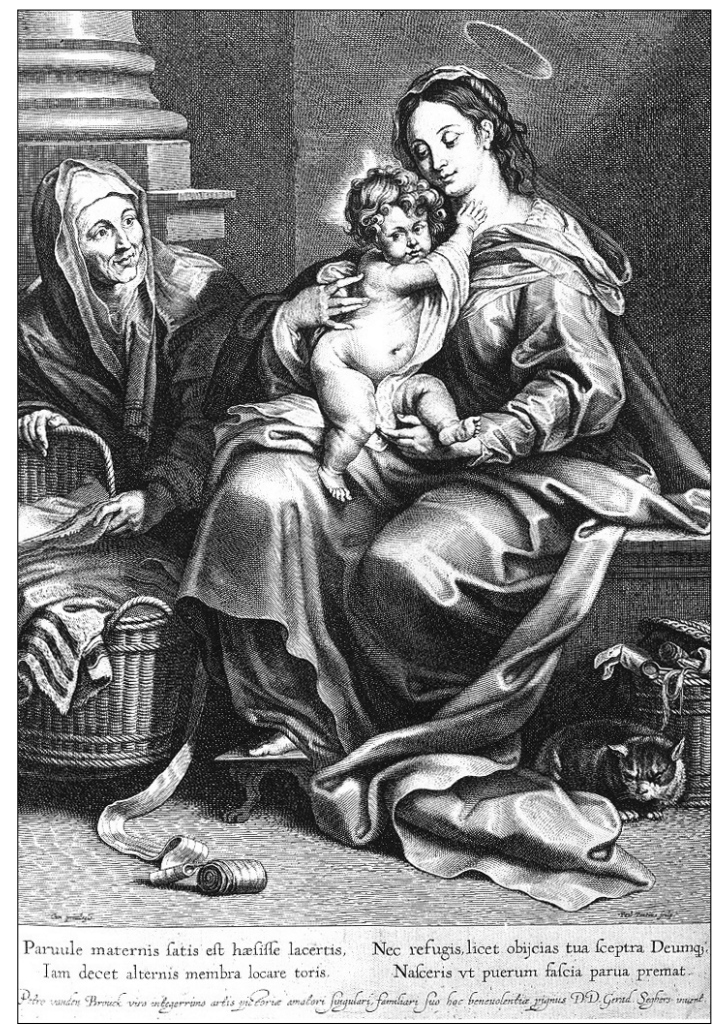

Fig. 2. Paul Pontius según Gérard Seghers. Virgen con el Niño y Santa Ana. Grabado.

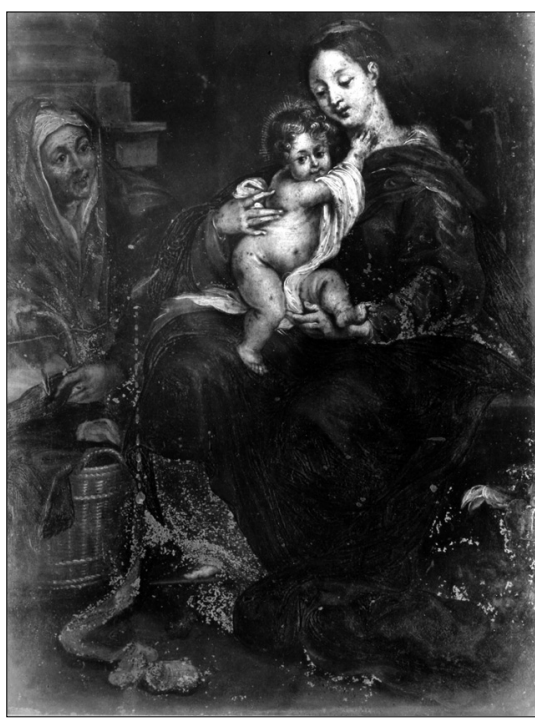

Fig. 4. Anónimo según Gérard Seghers. Virgen con Niño y Santa Ana. Zaragoza, colección particular.

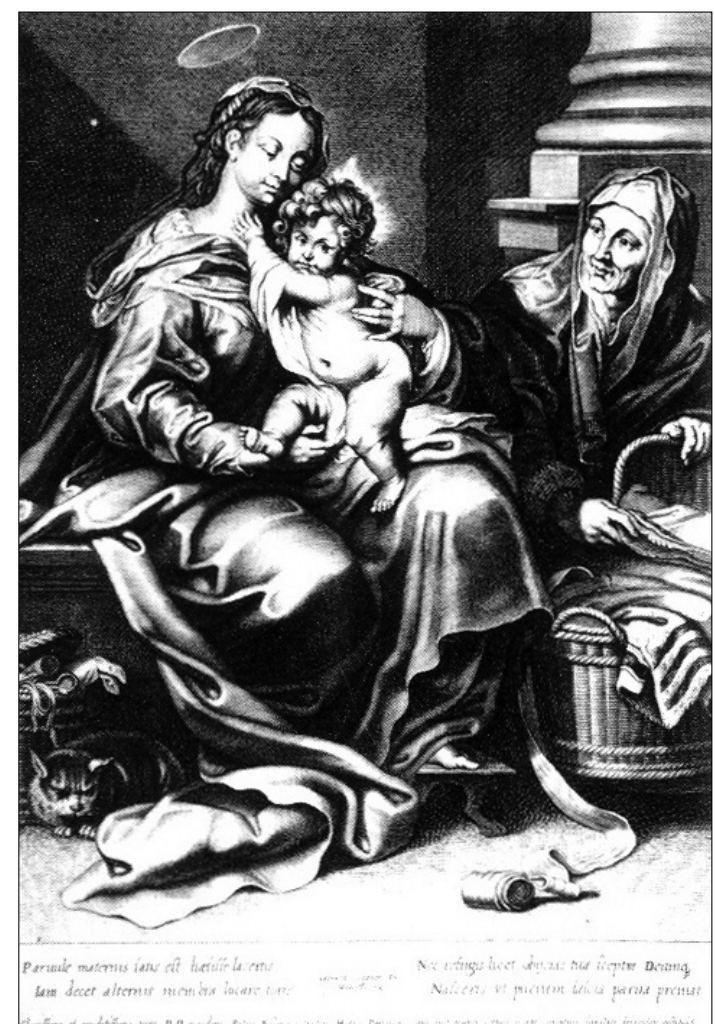

Fig. 3. Giovan Battista Falda. Fuente superior del Teatro del bosque de la Villa Ludovisi en Frascati.

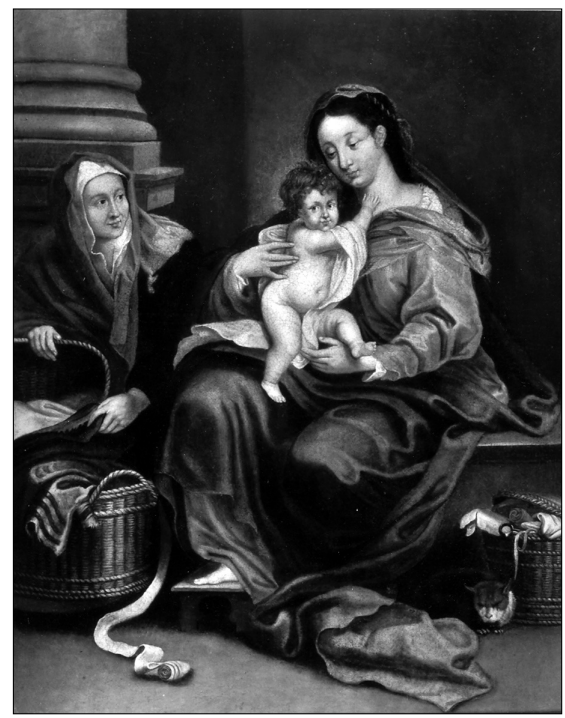

Fig. 5. Anónimo según Gérard Seghers. Virgen con el Niño y Santa Ana. La Haya, Kunsthandel H. Jüngeling (1961). 
que sirve de fondo y la mirada de la Virgen dirigida al espectador, la pintura se asemeja a la que no ocupa en modelos y composición.

La imagen está en acuerdo con el instinto maternal. Se hace énfasis en la intimidad materno filial, como diálogo amoroso entre la madre y el hijo, humana y ajena al hieratismo y la majestuosidad de otros tiempos, lo que responde al sentimiento devoto de la Contrarreforma. El carácter monumental de la composición sigue esquemas italianos de tradición renacentista que recuerdan a Andrea del Sarto. El fondo sombrío está en consonancia con el gesto de presagio que tiñe el rostro de María. El modelo de la Virgen, de grandes ojos con párpados redondos y rostro ovalado, el anguloso plegado de las telas y el dibujo de factura prieta coincide con el estilo de Gérard Seghers de la década de 1630, en la que acusa el influjo de Rubens. No obstante la paleta de Seghers es más clara, la factura más lisa y el modelo de la Virgen más estático y cercano a los esquemas renacentistas. La inscripción del grabado de P. Pontius no aporta dato alguno que nos permita situar la pintura cronológicamente, pero sabemos que la actividad de Paul Pontius con Seghers se sitúa después de 1631, momento hasta el cual el grabador trabajó para Rubens. La fecha propuesta por la doctora Bieneck -a principios de los años 164018-, nos parece demasiado tardía. Teniendo en cuenta la dependencia en composición y estilo con pinturas anteriores del maestro, pensamos que habría que pensar en la primera mitad de la década de 1630.

La Virgen con el Niño y Santa Ana de colección privada de Barcelona (Fig. 6) ${ }^{19}$, es pintura sobre cobre de pequeño formato, réplica reducida y con escasas diferencias del lienzo con la Virgen, el Niño y Santa Clara que conserva el Museo de Bellas Artes de Amberes (Fig. 7) ${ }^{20}$. La obra debió tener cierta fama, pues estaba en la capilla de los peleteros en la Catedral de Nuestra Señora de Amberes, ornando la tumba de Laurent Vits y su esposa Maria Menten. Igual que en nuestro cobre, la Virgen lleva túnica roja y manto azul, y el Niño, con camisa blanca y de perfil, bendice con la mano derecha mientras dirige la mirada a la santa, que lo observa con las manos cruzadas sobre el pecho en actitud de adoración. La presencia en el lienzo de Santa Clara de Asís, patrona de la orden de las Clarisas, se explica por la custodia eucarística con la que venció a los Sarracenos, episodio que se tomó para defensa del sacramento de la Eucaristía, tan en boga en el clima de la Contrarreforma. Seghers modificó esta figura en el cobre, sustituyéndola por Santa Ana.

Muy similares son ambas composiciones; no obstante, algunas diferencias se logran apreciar, diferencias que, lejos de apoyar la hipótesis de una copia servil, apuntan a su autoría por parte del maestro. De un lado, el asunto del relieve antiguo que está junto a la columna del fondo es en el lienzo una batalla o una cacería con un personaje a caballo y, en el cobre, una escena con un sacrificio. Difieren también las frutas en la copa que lleva María, la figura que acompaña y las aureolas sobre las cabezas, ausentes en el lienzo de Amberes. Todo indica que el pintor se permitió introducir algunos sutiles cambios en esta versión del tema, más simplificada y sin duda destinada a la devoción privada. De otra parte, la composición del cobre, más amplia en todos sus márgenes, permite suponer que es posible el lienzo de Amberes fuera cortado, que mostrara en su origen la figura completa de la santa y quizá el mismo sillar con voluta que vemos en el cobre. Así mismo, el relieve del fondo, cortado en el lienzo, se muestra en el cobre en su totalidad. De ser así, el cobre sería un valioso documento que restituiría la composición original del lienzo conocido de Amberes. Desde el punto de vista estilístico no se aprecian diferencias cualitativas notorias, salvo quizá un deseo de simplificación y cierta premura que se explican por la naturaleza y formato del soporte en cobre, así como por su destino al ámbito privado.

\footnotetext{
18 BIENECK, op. cit. 1992, p. 97.

${ }^{19}$ Cobre, $22 \times 17 \mathrm{~cm}$. Barcelona, colección particular.

${ }^{20}$ Lienzo, 113 x 86 cm. Amberes, Koninklijk Museum loor Schone Kunten [Inv. nº 511]. Véase Bieneck 1992, p. $236, \mathrm{n}^{\circ} \mathrm{A} 142$.
} 
Ya el siglo XVIII Houbraken comentaba que "las mejores obras de Gerard Seghers están en España" 21 , por lo que no ha de extrañar la cantidad de obras suyas presentes en nuestro país. Su nombre aparece repetidas veces en el inventario de la colección de pinturas de Don Diego de Messía, Marqués de Leganés (1655), uno de los mayores conocedores de pintura de su tiempo ${ }^{22}$, que poseyó más de treinta obras de Seghers ${ }^{23}$. También se cita en los inventarios de la Corona española desde el siglo XVIII ${ }^{24}$ pero, a pesar de la presencia de obras de su mano en España, y del eco que de su viaje hacen los tratadistas contemporáneos ${ }^{25}$, ningún dato confirma que este pintor se desplazara a la Península Ibérica. Aunque no sabemos con seguridad la duración precisa de su soggiorno en Italia, hay constancia de su ausencia de Amberes entre 1611 y $1620^{26}$. No obstante, como señaló Díaz Padrón en el Congreso Hispano-Belga de 1981, la omisión de un viaje a España en las fuentes españolas ${ }^{27}$ conduce a pensar que la mención de los tratadistas flamencos sea una invención, al no encontrarse en nuestro país rastro alguno de su paso ${ }^{28}$.

21 "Seine beste Werke sind in Spanien" [A. Houbraken, De groote schouburgh der Nederlantsche kontschilders ..., I, (1753), 1880, pp. 408-409.

22 Así lo declara Rubens en carta a Pierre Dupuy, el 27 de enero de 1628 [R. McGurn, The Letters of Peter Paul Rubens, 1955, No. 145].

23 J. LÓPEZ NAvío, "La gran colección de pinturas del Marqués de Leganés", Analecta Clasantiana, No. 8, 1962, N 170, 171, 173, 201, 209, 215, 218, 219, 220, 221, 266, 270, 271, 273, 275, 296, 299, 343, 369, 552, 554, 558, 559, 1153.

${ }^{24}$ Nos parece interesante señalar que en el siglo XVIII su nombre se cita en los Inventarios Reales, confundiendo sus obras con Rubens y Van Dyck. Así, el inventario del Palacio del Buen Retiro, en 1747, le atribuye el lienzo de Aquiles descubierto por Ulises y Licomedes de Rubens y Van Dyck en el Museo del Prado [n 1661], [“(1075): Otro de tres varas en quadro historia de Aquiles original de Gerardo Segres en veinticuatro mil reales", Inventarios Reales, Real Sitio del Buen Retiro, 1747, Ms, Vol. VII, $\left.\mathrm{n}^{\circ} 11355\right]$. Sin embargo, en la misma época una obra suya figura atribuida a la escuela de Van Dyck [(57): "Vna pintura original en lienzo de la escuela de Van Dyck el Señor en casa de Lázaro en acción de hablar a Marta quien está a un lado con prevencion de aves tiene siete tercias y tres dedos de alto y dos varas y media y vn dedo de ancho" [Inventarios Reales. Palacio del Real Sitio de San Ildefonso. La Granja, 1746-47, MS, Vol. VII, $\mathrm{n}^{\circ}$ 11524]. Se trata de Cristo en casa de Marta y María del Museo del Prado (nº 1914).

25 Cornelis de Bie en el siglo XVII hace eco de la presencia de Gérard Seghers en España: "largo tiempo permaneció en Italia como en España, donde el rey le honró con el título de servidor de la Casa Real” [C. de Bie, Het gulden cabinet van de edel vry schilderconst, Amberes, 1661, p. 96]. Posteriormente, Sandrart, Descamps, Félibien, Isaac Bullart y Florent le Comte afirmaron este hecho: "Gerad Zegres ou Segers, d'Anvers, travailloit aussi dans ce temps-là. Il étoit né l'an 1592 \& fut disciple de Janssens. Il voyagea en Italie et en Espagne, ou il peignit pour le Roy Catholique (...)" [A. Félibien, Entretiens sur les vies et sur les ouvrages des plus excellents peintres anciens et modernes, III, Paris, 1679, p. 148]. “(...) Il y eust peutestre fait un long sejour [En Italie], si le Cardinal Zapata, Ambassadeur de Sa Majesté Catholique auprès de Sa Sainteté, ayant ony parler du merite de son pinceau, ne l'eust pressé instamment de le suivre à son retour en Espagne. Ce Cardinal estant arrivé à Madrid le presenta au Roy, qui le vid de fort bon œil \& lui fit peindre plusieurs pièces d'importance pour ses Palais, \& pour quelques lieux de devotion, où cet habile homme laissa des marques éclatantes de farare experiences en la Peinture. Aussi ce Monarque grandement satisfait de son travail, après l'avoir honoré de sa bienveillance pendant qu'il demeura à Madrid, le fit Gentil-homme, \& lui donna une pension considerable sur le Château d'Anvers, lors que pressé par ses prieres il ne put lui refuser la permission de retourner dans sa Patrie" [I. Bullart, Académie des Sciences et des Arts, contenant les Vies et les Eloges Historiques des Hommes illustres qui ont excellé en ces profession depuis environs quattre siècles parmis diverses nations de l'Europe, II, Bruxelles, 1682, pp. 493]. Lo mismo repite F. Le Compte [Cabinet des singularités d'Architecture, Peinture, Sculpture et Graveure ou Introduction à la Connaissance des plus Beaux Arts..., Bruselas, 1702, p. 161].

26 D. BoDART, «Le voyage en Italie de Gerard Seghers», Studi offerti a Giovanni Incisa della Rocchetta, Micellanea della Socità Romana di Storia Patria, XXIII, 1973, pp. 79-88C. van de Velde, "In de ban van Caravaggio en Rubens : de schilder Gérard Seghers", Revue Belge d'Archéologie et d'histoire de l'Art, LXI, 1992, p;184.

27 Sólo Lázaro Díaz del Valle menciona su presencia pero, sin embargo, sus noticias no son de primera mano [Cit. Díaz Padrón, op.cit. 1982]. Dos lagunas existen en la vida del pintor: la primera, entre 1611 y 1620, durante la cual se sabe que estuvo en Italia; y en la segunda, entre 1624 y 1626 se piensa estuvo en Utrecht y fue llamado por el rey para viajar a España

28 DíAZ PADRÓN, op.cit. 1981, p. 2. 


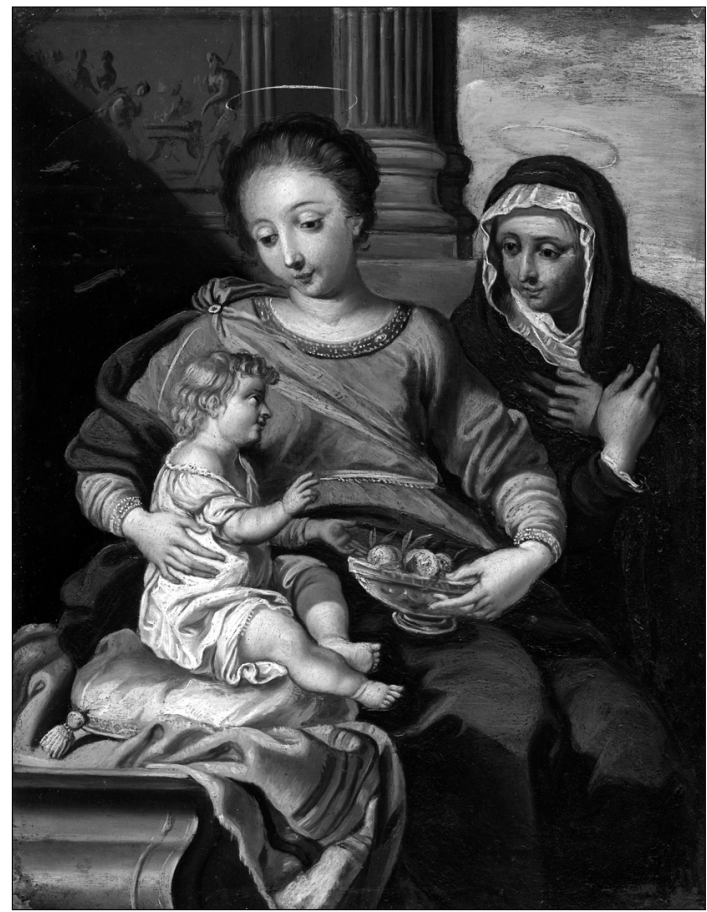

Fig. 6. Gérard Seghers. Virgen con Niño y Santa Ana. Barcelona, colección particular.

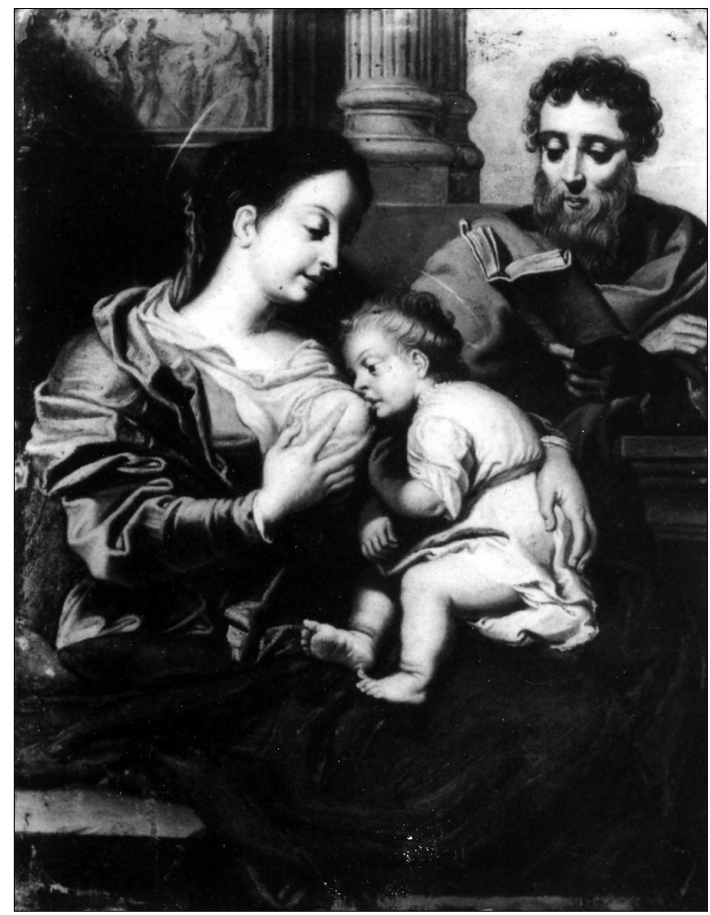

Fig. 8. Gérard Seghers. Sagrada Familia. Roma (Finarte, 1987). Paradero actual desconocido.

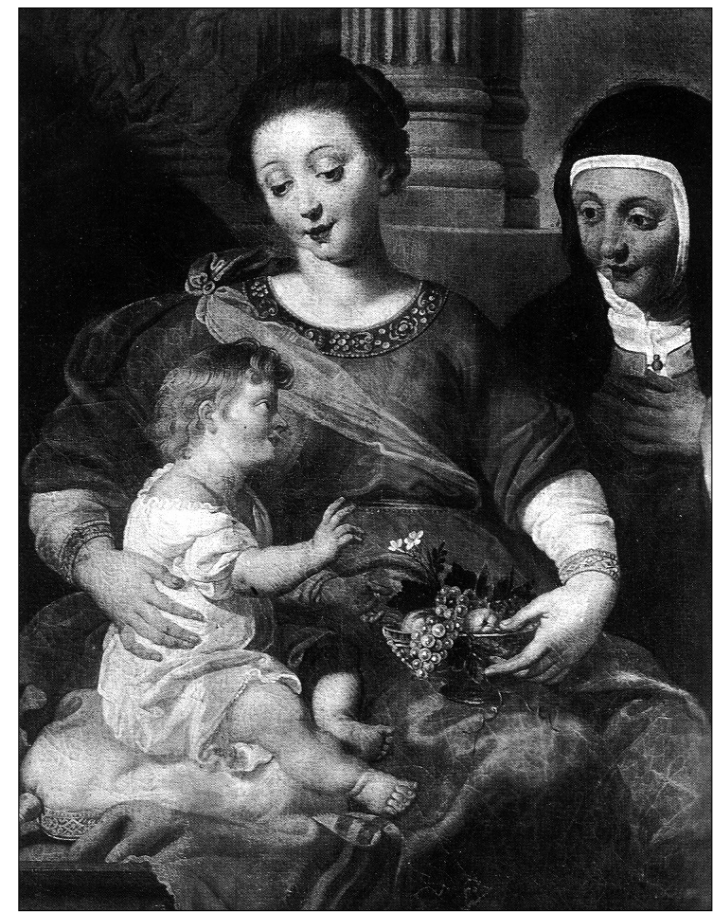

Fig. 7. Gérard Seghers. Virgen con Niño y Santa Clara. Amberes, Museo de Bellas Artes.

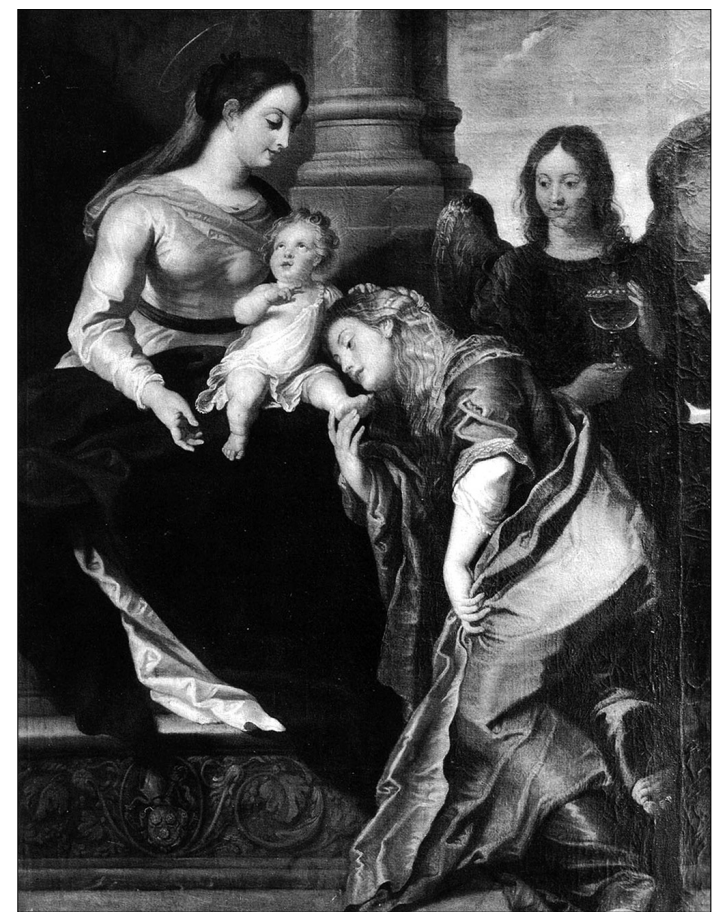

Fig. 9. Gérard Seghers. María Magdalena arrodillada ante la Virgen y el Niño. Tournai, Catedral de NôtreDame.

AEA, LXXX, 319, JULIO-SEPTIEMBRE 2007, 307-334, ISSN: 0004-0428 
Gérard Seghers sirvió con sus pinceles a la Corona española y estuvo unido a España en igual medida que Peter Paul Rubens, Antoon van Dyck, Jacob Jordaens o Gaspar de Crayer, sin necesidad de pisar las tierras de la Península Ibérica. De hecho, desde 1630 él mismo se declara "Peintre entretenu de Sa Majesté". La abundancia de sus obras aquí se explica por el favor de las Cortes españolas de Madrid y Bruselas, y por sus contactos con el cardenal español Antonio Zapata ${ }^{29}$, representante del rey Felipe III en Roma a partir de 1604 y lugarteniente y capitán general del reino en Nápoles en 1620, quien probablemente jugó algún papel en el envío de pinturas suyas desde Italia.

De Italia procede una Sagrada Familia que quisiéramos añadir al catálogo de obras del pintor, localizada en el comercio romano de hace dos décadas, con atribución à Willem van Herp (Fig. 8) ${ }^{30}$. Dicha atribución se debe al alargamiento de las figuras y a los modelos con las órbitas de los ojos pronunciadas, así como a las vibraciones de las telas, que pudieron prestar a confusión pero, si bien Van Herp se inspira a menudo en composiciones de Seghers, su estilo es bien diferente ${ }^{31}$. Aquí Seghers repite el esquema compositivo, con columna y relieve antiguo en el fondo. El modelo de la Virgen es idéntico en el lienzo con María Magdalena arrodillada ante la Virgen y el Niño de la Catedral de Nôtre-Dame de Tournai (Fig. 9) ${ }^{32}$, también repetido en la Virgen con el Niño y los pecadores arrepentidos que estuvo en la Iglesia de San Antonio de Amberes ${ }^{33}$. El rostro de San José es muy similar en los lienzos con El sueño de San José del Museo de Bruselas y de la colegiata Saint Vincent en Soignes ${ }^{34}$, así como en el gran lienzo con San Eloy a los pies de la Virgen del Museo de Valenciennes ${ }^{35}$.

Por último, llamó nuestra atención una pintura sobre cobre con Vertumno y Pomona, catalogada como anónima en el comercio de Londres (Fig. 10) ${ }^{36}$. Reconocimos la misma figura sentada que introdujo Seghers en el lienzo de Jesús en casa de Marta y María del Museo del Prado (Fig. 11) ${ }^{37}$, cuyo modelo deriva del original de Rubens perdido en Berlín. El asunto, como es bien conocido, está tomado de las Metamorfosis de Ovidio (XIV, 623), donde se relata el empeño de Vertumno por acercarse a la hermosa Pomona, que no cedía a los deseos de sus múltiples pretendientes, pues su único interés y afán era el cultivo de campos y jardines. De ahí la hoz que lleva en la mano derecha. Vertumno decide ocultarse bajo la apariencia de una anciana y convencerla así de la autenticidad del amor le profesa: "Incluso - dice el texto de Ovidio- se ciñó él las sienes con una cofia bordada y apoyándose en un bastón y colocándose canas en las sienes fingió ser una vieja y entró en el cuidado jardín". Seghers elige el momento en que así le aconseja: "Si eres lista, si quieres una buena alianza y estás dispuesta a escuchar a esta vieja, que te ama más que todos ésos, más de lo que tu piensas, rehúsa todo matrimonio vulgar y elige a Vertumno por tu

\footnotetext{
29 RoBloy-DÉlONDRE, op.cit. 1930, pp. 187-188; Van de Velde, op. cit. 1992, pp. 185-6.

30 Cobre, 21,5 x $16 \mathrm{~cm}$. Roma, Finarte, 2-VI-1987, nº 131 (como atribuido a Willem van Herp).

31 A propósito de Willem van Herp véase, por ejemplo, F. C. Legrand, Les peintres flamands de genre au XVIIème siècle, Bruxelles, éditions Meddens, 1963, pp.167-175; Díaz Padrón, M., "Obras de Guillaume van Herp en España I y II", Archivo Español de Arte, Madrid, 1977, No 200, pp. 365 y ss, 1978, № 201, pp. 10 y ss; Idem, "Nuevas pinturas de Guillaume van Herp", Miscelánea de Arte. Homenaje a Don Diego Angulo, Madrid, 1982; Sanzsalazar, J., "Un Banquete Familiar de Willem van Herp en Bad Harzbourg", Goya, 297, nov-dic 2003, pp. 356-359; Idem, L'oeuvre de Willem van Herp (1614-1677), Bruselas, Vrije Universiteit, Tesis Doctoral bajo la dirección del Profesor A. Balis (en preparación).

32 Lienzo, 190 x $140 \mathrm{~cm}$. Véase Bieneck, op.cit. 1992, p. 170, nº A47.

${ }^{33}$ Lienzo, medidas y paradero actual desconocidos. Véase Bieneck, op.cit. 1992, p. 171, nº A48.

34 Véase Delvingt, op.cit. 2001.

35 Lienzo, 329 x 244 cm. Valenciennes, Musée des Beaux Arts, Inv. nº 46. 1. 162.

36 Cobre, 27.7 x $19.4 \mathrm{~cm}$. Christie's, Londres, 13-VII-2001, n 104.

37 Lienzo, 205 x 215. Madrid, Museo del Prado [inv. 1914], Véase Bieneck, op.cit. 1992, p. 152, nº A.25; M. Díaz Padrón \& A. Padrón Mérida, El Siglo de Rubens en el Museo del Prado, Madrid, 1995, vol. II, p. 1208, nº 1914.
} 


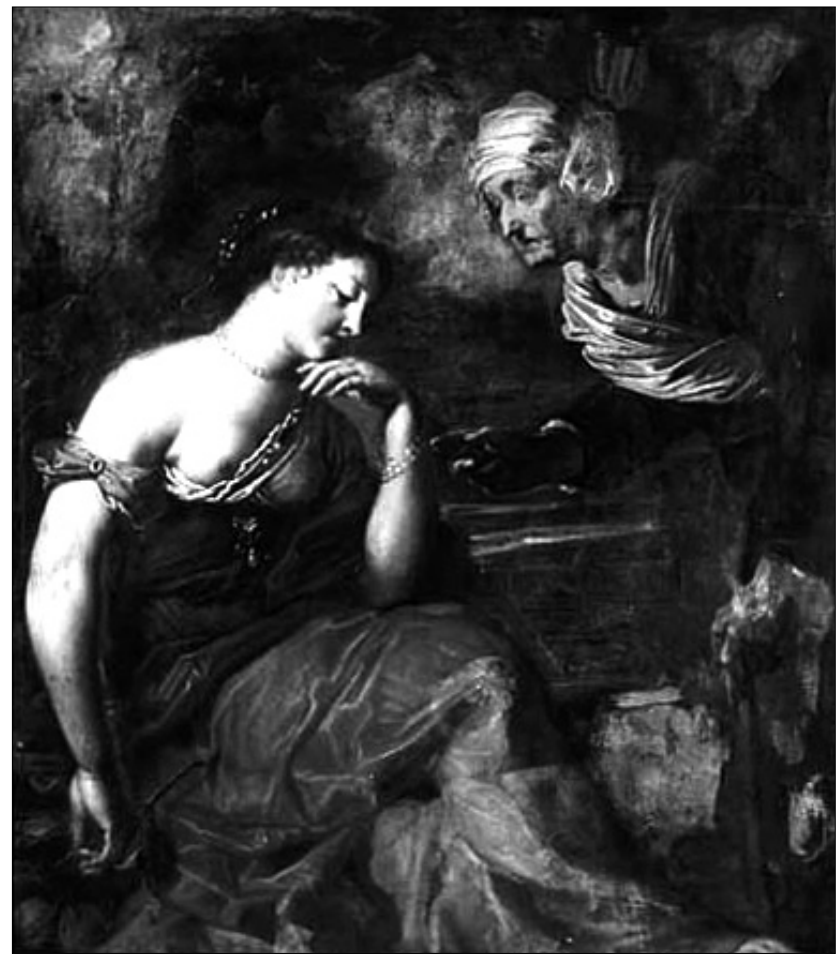

Fig. 10. Gérard Seghers. Vertumno y Pomona. Paradero desconocido.

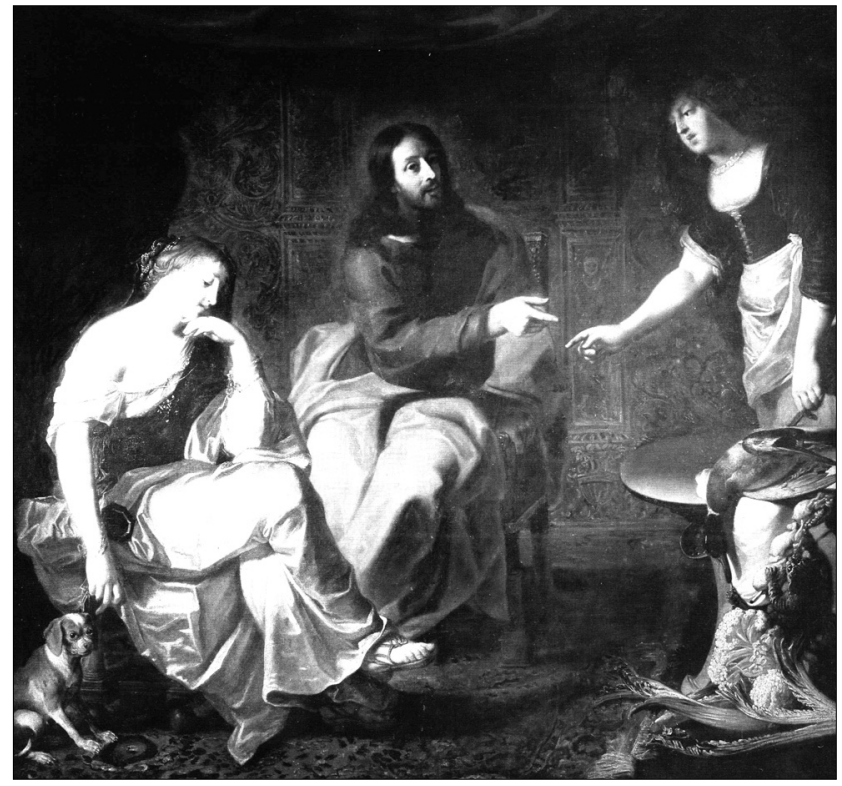

Fig. 11. Gérard Seghers. Cristo en casa de Marta y María. Madrid, Museo del Prado. 
compañero de lecho. Aquí me tienes también como fiador de él; porque ten la seguridad de que no se conoce él a sí mismo mejor que yo lo conozco; y no anda errante por doquier a través del mundo entero; habita estos vastos parajes; y no hace como la mayor parte de tus pretendientes, amar a la última que han visto: tu serás su primera y su última pasión y sólo a ti consagrará sus años".

Salvo la hoz que lleva en su mano derecha, pocas son las alusiones a la actividad jardinera de Pomona, asunto que por lo común sirve de pretexto a los pintores para mostrar sus excelencias en la representación de frutas y hortalizas. Esto no es extraño en Gérard Seghers, quien a juzgar por su obra conocida no parece inclinado por la Naturaleza Muerta. Sin embargo, la posición del brazo y de la mano de la joven, modificada respecto a la figura de María en el lienzo del Museo del Prado, está acorde con la herramienta que sostiene. La anciana no es ajena al modelo de Santa Ana en el grabado de Pontius anteriormente reproducido; y su gesto parlante recuerda al de la esposa que injuria a $J o b$ en el muladar ${ }^{38}$.

El hallazgo de estas pinturas sobre cobre de mano de Gérard Seghers muestra una faceta en su producción hasta ahora insospechada ${ }^{39}$, a saber, que no sólo fue "très expert peinctre en grand", según la inscripción que acompañó a su retrato grabado por Peter de Jode ${ }^{40}$, sino que también empleó sus pinceles en pinturas sobre cobre y de pequeño formato.

JAHEL SANZSALAZAR

${ }^{38}$ Lienzo, 192 x 242.5 cm. CSFR, Staatsscloss Jindrichuv Hradec (Neuhaus), Inv. 302 [Bieneck, op.cit 1992, p. 197, $\left.\mathrm{n}^{\mathrm{o}} \mathrm{A} 84\right]$

${ }^{39}$ Sobre soporte de cobre es conocido un Cristo despidiéndose de la Virgen [Cobre, 101 x $78 \mathrm{~cm}$. Nimes, Musée des

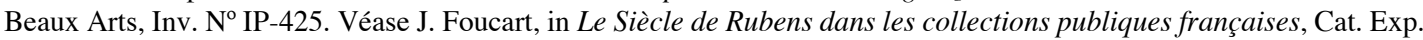
París, Grand Palais, 1977-1978, p. 216, n 167].

40 Véase el autorretrato que sirvió al grabado y lo relativo a la inscripción "très expert peinctre en grand a fait beaucoup de belles pièces principalment en devotion”, en Delvingt, op.cit 2005, p. 112. 